\title{
As funções da instituição escolar: análise e reflexões. *
}

\section{Cecilla Maria B. Coimbra **}

A credito ser de fundamental importância para nós, trabalhadores em educaçào, no sentido de tornar nossa atuação um pouco mais erítica, que repensemos sobre as funçöes que a instituiçảo escolar exerce em nossa sociedade.

Tal enfoque da Escola nos deve auxiliar nào somente a entender melhor o cotidiano do nosso trabalho, como também nos alertar para as múltiplas armadilhas que a todo momento sảo montadas e nas quais muitas vezes caimos sem mesmo perceber.

Tentaremos mostrar como sảo ingènuas e mesmo idealistas as visỏes que nos apresentam da instituiçào escolar. Visōes essas que estào claramente marcadas pelos mitos da igualdade social e oportunidades para todos, da neutralidade e cientificidade, que principalmente a Escola se incumbe de fortalecer e desenvolver. Mitos que colocam a Escola acima da luta de classes, isolando-a de uma formaçào social especifica.

Ao longo de vários anos como professora e psicóloga pude notar que nós, trabalhadores em educação, temos nossa formação acadèmica marcada por vicios e lacunas que têm cla. ramente um objetivo político-ideológico. Somos os profissionais, muitas vezes, do superficial: enfatizamos a relaçào professor/aluno, a melhoria dos curriculos, a modernizaçāo das téenicas e métodos de ensino, desvin. eulando-os de todo um contexto his-

- Trabalho apresentado na Secáo de Abertura da Jornada de Psicologia Escolar, realizada pela Associaçào dos Psicólogos do Norte Flumi nense em Campos, em outubro de 1986.

* Psicóloga na Secrecaria Municipal de Educa çāo do Rio de Janeiro. Professora Adjunta e Supervisora de Estágjos em Psicologia Escolar na Universidade Federal Fluminense.
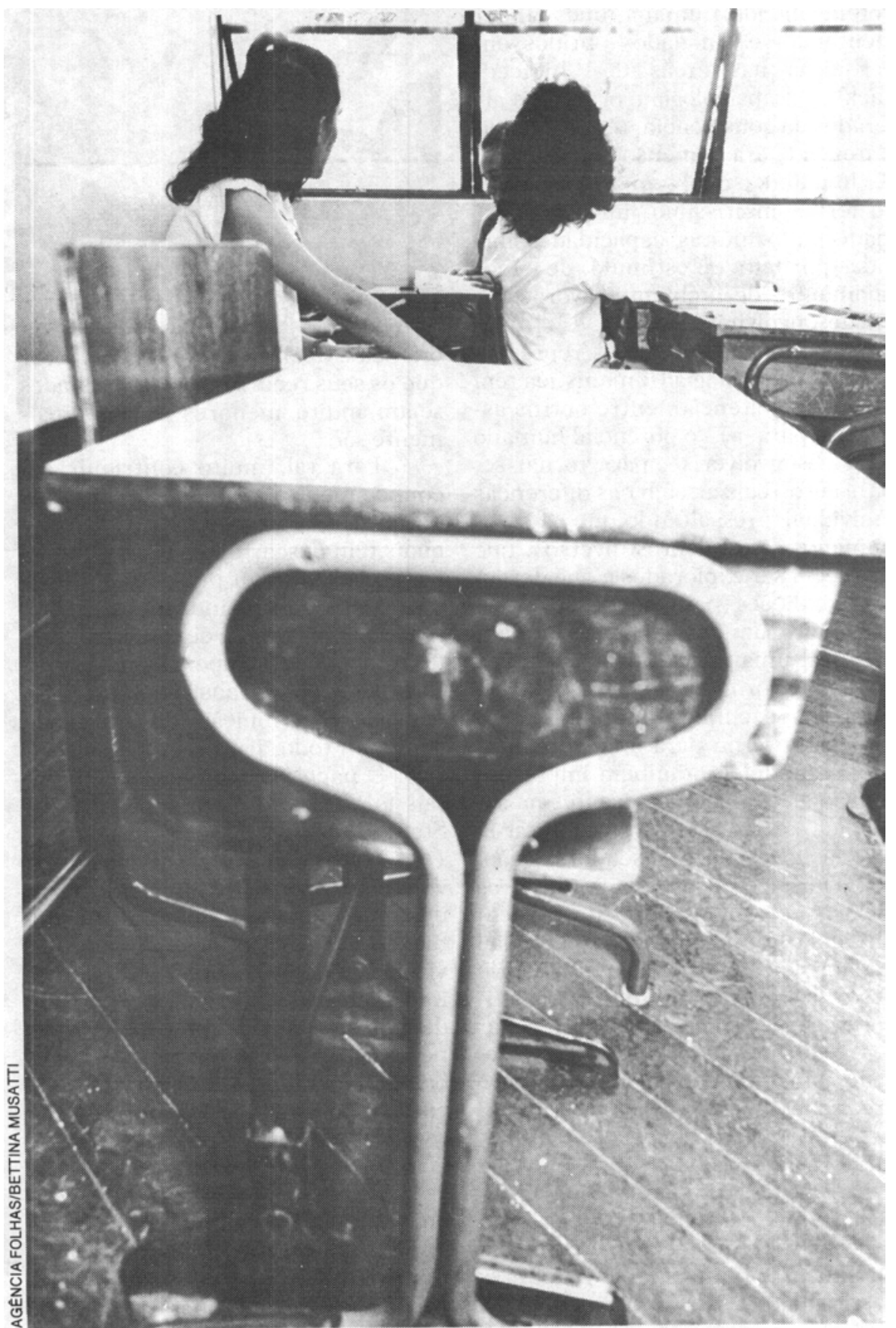
tórico, social, politico e econômico. Fomos ensinados a pensar as institui cöes como abstraçòes, como "coisas-em-si", como se as relaçōes de poder existentes em nossa formaça social ali nào estivessem presentes.

Raramente em nossos cursos de formaçào faz-se uma análise politica e ideológica de nossa funçāo enquanto educadores numa sociedade dividi. da em classes. "Estamos sendo formados para servir a quem? Para propiciar e desenvolver o quê? Para reforçar o poder de quem? Somos levados a refletir criticamente sobre o mundo que nos cerca? Sobre como nos inserimos neste mundo e como poderíamos dele participar de forma mais ativa e transformadora? Tais questōes nào sào debatidas e muito menos pensadas" (6). Sobre este assunto é importante e valiosa a pes. quisa feita por Maria Helena Patto, em sua tese de doutorado (11), entre psicólogos da rede pública de Sào paulo, que mostra através da análise de uma série de respostas, a visāo de mundo daqueles psicólogos: os preconceitos e estereótipos quando falam das crianças que freqüentam as escolas públicas, a total ausência em seus discursos da divisāo da sociedade em classes, da existència de uma estrutura de dominaçào cultural arbitrária e da imposiçào de uma visào de mundo existente na instituiçào escolar.

\section{A Instituicäo Escolar tem História}

Sabemos que a educaçào sempre existiu; que educar era viver a vida do dia-a-dia da comunidade, ouvindo dos mais velhos as suas experièncias e com isso formando-se para atuar em comunidade. As festas coletivas, as tradiçōes eram, assim, pas sadas naturalmente, sem a necessidade de uma instituiçào especifica para isso. Portanto, nas formaçōes sociais mais antigas todos os adultos (os mais velhos) ensinavam. "Aprendia-se fazendo, o que tornava inseparáveis o saber, a vida e o trabalho.

Foi somente a partir da Idade Média que, na Europa, a educaçào se tornou produto da escola e um conjunto de pessoas (em sua maioria religiosos) especializou-se na transmissảo do saber" (10:25-26). Entretanto nesta época, embora o ensino fosse reservado às elites (principalmente à nobreza), não havia separaçōes entre crianças e adultos e a Escola nảo es. tava organizada para disciplinar seus alunos (2).
É a partir do século XVII que vemos a Escola surgindo como instituiçà, nos moldes em que a conhecemos atualmente.

Portanto, o aparecimento desta instituiçāo estâ visceralmente ligado ao desenvolvimento do capitalismo. Com a Revoluçāo Industrial, a partir de 1750 , sentiu-se a necessidade de am numero maior de pessoas que soubessem pelo menos ler, escrever e contar. Pessoas essas que seriam jogadas nas nascentes industrias, fornecendo mào-de-obra para o manejo das máquinas. Por outro lado, a burguesia jả no poder percebeu tambèm a necessidade de "socializar" e "educar" a massa trabalhadora existente nos grandes centros urbanos, para formá-los como "bons" cidadàos e trabalhadores disciplinados. Com isso, vemos a Escola surgindo com clàras funçòes: inculcar os valores, hábitos e normas da classe que domina, ou seja, inculcar a ideologia burguesa e, com isso, mostrar a cada um o lugar que deve ocupar na sociedade, segundo sua origem de classe.

Segundo muitos autores, como Althusser, Bourdieu, Passeron, Baudelot, Establet, Poulantzas e outros $(1 ; 4 ; 5 ; 7 ; 12)$ a instituiçāo esco. lar passa a ser a peça fundamental para o desenvolvimento e fortaleci . mento do capitalismo. Consideram a Escola como Aparelho Ideológico de Estado, pois é o instrumento número um da burguesia, visto difundir a sua visào de mundo e de vida. Aliados a este aparelho, temos outros que o complementam e refor cam: a familia e os meios de comu. nicaçāo, principalmente.

Estes ültimos fazem um trabatho "soberbo", pois conseguem criar na opiniào pública o que Gramsci (9) chamou de consenso. Com ele, a burguesia mantèm sua hegemonia e dominaçāo, naturalízando tudo o que é produzido e forjado pelo capitalismo.

Assim tudo passa a ser visto de forma natural, como se a Escola fosse neutra e desse iguais oportunidades a todos, tratando da mesma forma os que a ela tèm acesso.

Ao fazermos este pequeno histórico do surgimento da instituięào escolar, alguns mitos passam a ser questionados, como por exemplo:

- a Escola surge para fortalecer e garantir o poder de uma classe social que é dominante numa determinada formaçảo social, ou seja, ela nem sempre existiu, é criada para servir a determinados objetivos. Não é, portanto, resultante de um processo imprescindivel para o desenvolvimento da humanidade, da civilização e da cultura. Ela é datada historicamente. Cai, com isso, o mito de que a Escola sempre existiu, atendendo a uma "necessidade natural"',

-a Escola, que se coloca como neutra, tem por finalidade ensinar os valores, hábitos e costumes de uma determinada classe social, colocando-os como naturais e unversais. Ao lado das informaçōes chamadas cientifi. cas e mesmo embutidas nelas, temos uma ideologia que mostra o que é certo e o que é errado, o que é bom e o que é mau. A competiçào, a submissāo à ordem estabelecida, o medo às autoridades, o respeito à hierarquia sảo mostrados e ensinados como se sempre tivessem existido e, portanto, passam a ser percebidos como naturais. E neste lugar que se aprende, com esses valores, a se tornar um "bom" e "respeitável" cidadào. A hierarquia que existe em nossa sociedade ali se reproduz e nisso a disciplina desempenha um papel fundamental, através das puniçóes e castigos. É o que Foucaul (8) chama de poder disciplinar, um dos dispositivos sociais mais importantes, notadamente na Escola. Esta, portanto, nào é fonte de enriquecimento pessoal e social. E, ao contrario, local onde as práticas da classe dominante sào ensinadas e fortalecidas, prâticas que são essencialmente políticas. Com isso, cai o mito da neutralidade e cientificidade da Escola.

- a Escola que se coloca aberta a todos, que é vista como democrática, e trata a todos da mesma forma, nào tem responsabilidade pelos fracassos escolares. O grande número de repetências e evasỏes passa a ser explicado como responsabilidade dos alunos e suas familias. Se nào conseguem aprender é porque sào inferiores, mal alimentados, carentes material e emocionalmente. Com isso, a Escola inculea um outro mito, o da inferioridade e marginalidade desses alunos que, de um modo geral, pertencem às classes populares. Ou seja, passa a ser natural os filhos da classe trabalhadora nào aprenderem, pois sào inferiores. Escamoteiam-se, assim, todas as práticas de exclusāo existentes no interior da Escola, que selecionam e sảo responsáveis pela divisāo: bons e maus alunos. De um lado, temos uma minoria que vai continuar os es. 
tudos e alcançar a Universidade; de outro, uma maioria que, se nào sair da Escola, vai seguir cursos mais curtos e menos valorizados socialmente. Esta separaçāo, afìma a Escola, é feita segundo critérios exclusivamente pedagógicos. Os "melhores", os mais inteligentes e os estudiosos ob. têm os melhores resultados. Entre. tanto, percebemos que tais resultados estão estreitamente ligados à ori. gem de classe desse alunos. Sáo os oriundos das classes média e alta, os considerados "melhores". Assim, a Escola, em seu interior, reproduz e fortalece a divisào de classes que existe em nossa sociedade. Pelo censo de 1980, no Brasil a maioria das crianças que abandona os estudos antes de completar os 8 anos de escolaridade obrigatória vem de familias pobres, do meio rural e dos bairros populosos das periferias das grandes cidades. Com isso, cai o mito da Escola democrática e aberta a todos.

$\mathrm{E}$ entre esses mecanismos de exclusāo utilizados pela instituiçào escolar, quais sào, a nosso ver, os principais? Essas práticas que excluem e selecionam os alunos segun. do sua classe social estâo presentes nos currículos, nos conteúdos que somente retratam e descrevem uma realidade burguesa, nos métodos de avaliaçào, pois é o professor que decide o que é ou nào importante de ser aprendido pelo aluno, ou seja, a avaliaçào è considerada patrimônio exclusivo do professor e um fim em si mesmo. Estāo tambèm presentes nos testes psicológicos aplicados por muitos de nós, para verificar se os alu. nos estào máduros ou nào para serem alfabetizados, para homogeneizar as turmas, através do quociente intelectual e mesmo para diagnosticar se sào normais ou anormais os portadores das chamadas dificuldades de aprendizagem. Nào pretendo entrar em detalhes sobre a origem positiva, as funçōes ideológicas e de controle dos testes psicológicos (3), mas acredito ser importante enfatizar que tais testes sào construidos tendo por base conteúdos desvinculados da realidade brasileira e uma amostragem pertencentes às classes média e alta. Principalmente os testes de inteligência sào instrumentos utilizados para discriminar as crianças oriundas de classes populares que são vistas como menos inteligentes que as demais. Assim, mais uma vez utilizando instrumentos considerados cientificos, os técnicos dào seu aval e ajudam a naturali- zar as falhas e os fracassos escolares. Conctulndo

Resumidamente, citamos uma série de aspectos com os quais lidamos dia-a-dia e que são naturalizados, reforçados e confirmados por muitas teorias e técnicas consideradas cientificas.

E nós, educadores, nisso tudo?

De um modo geral, acreditamos nesses mitos, reproduzimos e transmitimos toda essa ideologia através da utilizaçāo dessas práticas de exclusāo, percebendo-as como naturais e, portanto, como neutras. Nós próprios aceitamos nossa neutralidade e pouco desconfiamos que somos instrumentos importantes na transmissāo de toda essa ideologia dominante. Poucos sāo aqueles que refletem eriticamente sobre seu trabalho, sobre as funçòes que vêm exercendo e sobre tais mecanismos de exclusảo que a Escola cotidianamente coloca em funcionamento, utilizando nosso aval técnico e científico.

Mas, se a Escola tem tais funções, isso não nos levaria a uma postura imobilista e de impotencia? Isso não nos levaria a afirmar: se a Escola é assim, entảo nada podemos fazer?

Acreditamos que nào, pois apesar de a Escola ser uma instituiçāo fortemente articulada com o Estado, encontramos em seu interior espacos onde as lutas acontecem e as contradiçóes estāo presentes.

Apesar da angústia que este pa. norama da Escola pode nos trazer, é importante que possamos perceber que as instituiçoes produzidas para preservar as estruturas capitalistas, podem também ser utilizadas para minar estas mesmas estruturas. É o que Gramsei (9) denomina de contra-ideologias, que a todo momento eirculam nos mais diferentes espaços da Escola. I Iá que fortalecê-las e expandi-las para que uma pedagogia de emancipaçào possa assumir força politica.

Sem negarmos as dificuldades de uma atuaçào mais crítica na instituiçào escolar, ousamos afirmar que é trabalhando e aprofundando tais contradiçóes (sem camuflá-las e/ou neutraliza-las) que podemos criar e aumentar gradativamente novos espaços de luta dentro da Escola.

Tentamos no nosso cotidiano articular as lutas que ocorrem dentro da Escola com as lutas na sociedade em geral, pois percebemos que se localizarmos e especificarmos demais um problema, recortando-o e isolan- do-o de um contexto mais amplo, es taremos caindo na armadilha de nos alienarmos do momento histórico, social, econômico e político no qual esses problemas e nós mesmos estamos inscritos.

Em nossa atuaçāo, podemos fazer mais do que simplesmente denunciar as funçōes da instituiçāo es. colar em nossa sociedade e, nós, educadores, nāo podemos ignorar isso em nosso trabalho. Pretendemos, sim, operar uma ruptura e tornar possivel uma outra lógica, uma outra realidade. Assim, se a Escola hoje é um espaço produzido pelos dominantes, mas se nela encontramos fissuras e campos para atuaçào, podemos através de nossa prática agudizar suas contradicòes e conflitos, bus. eando a todo momento questionar os modelos que nos são impostos como verdadeiros e procurar caminhos, que nào os apresentados oficialmen. te, que nos permitam expandir forças que possam interferir no cotidiano dos diferentes mitos veiculados pela Escola e em suas práticas de exclusào.

1 ALTHUSSER L-Ideologia e Apareilhos Ideotógions do Estado. Sào Paulo, Martins Fontes, s/d.

2. ARIES, P. - Historia Social da

Criança e da Familia - Rio de Janeiro, Zahar Editores, 1978 .

3. BARROS, R. D. de - Testes na Escrola: Próticas de Caprura - Trabalho apresentado no $\left.\right|^{7}$ Ciclo de Lebates de Psicologia Escolar e [l' Ciclo de Debates sobre a Deficièncin, Ĺniversidade Federal Fluminense, 1985. (Para aprofundamento maior sobre a ucilizaçik dos testes psicológjicos na Escola).

4. BAUDELOT, C. \& Establet, R. - LEcole Capitaliste en France - Paris, Maspero, 1971

5. BOUDIEU, P.\& PASSERON, J.C. - A Repryduçán: Elementos jara uma temia do siste. ma de ensino Rio de Janeiro, Francisco Alves, 1975.

6. COIMBRA, C.M. B. - Desvies e Lacunas na formaça do Psicólogo: a quem servem? Revista Pro-Psi, Oonselho Regional de Psicologia, 5 (6): 10.11, ano 2, secembro, 1985.

7. ESTABLET, R. - A Escola In. As Institui cóes e os Discursos. - Revista Tempo Brasi leim, Rio de Janeiro, (35): $9.3-125$, out/dez 1973

8. FOUCALIJ, M. - Microfistce do Poder, Rio de Janeiro, Graal, 1979

9. GRAMSCI, A - Os intelectuais e a Organi zaçio da Cultura $\rightarrow$ Rio de Janeiro, Civiliza çào Brasileira, 1982

10. HARPER, B. et alit-Cuidado, Eseo la!'Sáo Paulo, Brasiliense, 1980, p. 25/26. 11. PATTO; H. H. de S. - Psicologia e Ideolo gia: uma introduça crítica à psicologia es colar Sjo Paulo, T.A. Queiroz. Editor, 1984. (Tese de Doutoraklo).

12. POULANTZAS, N. - A Escola en Questàn In. As institujçóes e os Discursos - Revista Tempo Brasileiro, Rjo de Janeiro, (35); 126. 137 , out $/$ dez. 1973 . 